\title{
A REMARK ON BARRLUND'S LP METHOD
}

\author{
LAJOS LÁSZLÓ
}

Abstract. In possession of Friedland's theorem [3] on normal completion, Barrlund's linear programming method [1] can be adopted for sharpening the upper bound for the distance of a triangular matrix from the set of normal matrices.

Mathematics subject classification (2000): 15A45.

Key words and phrases: normal completion, scaled departure, linear programming.

\section{REFERENCES}

[1] A. BARRLUND, On a conjecture on the closest normal matrix, MIA, 1/3 (1998), pp 305-318.

[2] L. ELSNER, private communication.

[3] Sh. Friedland, Normal matrices and the completion problem, March 15, 2001.

[4] KH. D. IKRAMOv, On normal dilations of triangular matrices, Math. Notes, 60/6 (1996), pp 861-872 (Russian).

[5] L. LÁSZLÓ, Upper bounds for the best normal approximation, Sixth ILAS Conference, 1996, Chemnitz.

[6] L. LÁsZLÓ, Upper bounds for the best normal approximation, Math. Pannonica, 9/1 (1998), 121-129. 